\title{
Essay:
}

\section{Teaching Veterinary Anatomy During Covid-19 Pan- demic Time, Challenges and Solutions}

\section{Ashraf Sobhy Saber}

Fac. Vet. Med., Uni of Sadat City, EGYPT

\section{With 22 figures}

\section{Abstract}

How we managed the official suspension of the study in the Universities in Egypt since 14 March 2020 during the first attack of Covid-19 and also during the second Attack, is the point onto which lights will be focused in this essay. Challenges facing the anatomy/histology education were: How to manage the lectures, how to prepare the practical lessons, and how to make the exams specially the practical ones.

Two ways were adopted: presenting the power point program with audio comments to the groups of $1^{\text {st }}$ and $2^{\text {nd }}$ year students launched using WhatsApp. Some faculties managed a platform and the lecturers uploaded their power points on it, then the students download it. Instead of the written exams, an essay or small research article for each topic in anatomy/histology the students had studied was decided. The students have given 1.5 month as dead line to send their essays. The practical exams in replaced by $M C Q$, True and false, diagrams and short answers questions sheets. The evaluation is either pass or failed. The first end semester exams of this year were postponed to the beginning of the second semester i.e. 20 February 2021. The beginning of teaching the second semester is not yet decided. The general education policy now after this pandemic is a transfer to the electronic exams and corrections and in turn encouraging the universities to establish question banks for each syllabus and to adopt the Blended learning ( $50 \%$ online \& $50 \%$ face to face).

Keywords: Covid-19 Pandemic, Veterinary anatomy, Blended learning.

\section{Introduction}

How we managed the official suspension of the study in the Universities in Egypt since 14 March 2020 during the first attack of Covid-19 and during the second attack. 
The normal tools for studying comparative anatomy all over the world are:

- Museum facilities which are a major source of learning anatomy for the students, as it displays dry specimens (bones, skeletons, anatomical models, anatomy charts, air-dried specimens, plastinated organs and sheets, plasticine plates, corrosion casts), wet specimens (formalin preserved organs and animals and cross sections) as well as CDs and different anatomical images) (Figs 1-14).

- Anatomy modules (bringing the various teaching materials together to enhance self-directed integrated learning). (Fig 15).

- Lighted colored anatomical charts fixed on the walls in the halls, corridors of the museums and anatomy department areas (Fig 16).

- Some faculties installed Closedcircuit Television (CCTV) in the dissecting rooms to overcome the crowding and large number of the students around each table.

- Some faculties have Virtual 3-D model to teach cow anatomy. The 3$\mathrm{D}$ model shows the skeleton, heart, lungs, four-chamber stomach, spiral colon, liver, gall bladder, kidneys, uterus and ovaries, as well as the major blood vessels. (University of Illinois, USA). (Fig 17A)

- Other faculties (Royal (Dick) School of Veterinary Studies) developed an equine simulator which contains large intestines and other organs made of latex. These can be inflated to different degrees to help familiarize students with the condition. (Source: Wikipedia) (Fig 17B)

One of the advantages of using veterinary anatomy models is that students get an accurate depiction of various organs both structure and function and how correlate with each other; a concept that can be difficult to achieve when learning is restricted to textbook photographs.

Ozkadif and Eken (2012) mentioned that anatomy became a more pleasurable lecture by multimedia devices and other devices which were developed to use in anatomy education. On the other hand, Azer and Azer (2016) exploring three-dimensional (3D) anatomy models and their impact on learning, and to assess the equality of research in this area, concluded that there was no solid evidence that the use of $3 D$ models is superior to traditional teaching.

Challenges met with in our University in Sadat City, Egypt, in covid-19 pandemic, as example, were:

1) How to finish the lectures of the first semester?

2) How to finish the practical lessons?

3) How to make the exams specially the practical ones?

\section{Two ways were adopted to face this problem:}

- The University/faculty decided to use power point programs with 
audio comments and to send it to the groups launched for the $1^{\text {st }}$ and for the $2^{\text {nd }}$ year students using WhatsApp.

- Some faculties managed a platform and the lecturers uploaded their power points on it, then the students download it on their computers.

- Both methods were used and worked well.

At the beginning of the covid-19 pandemic time, all the aforementioned tools of learning anatomy were not available and the students have to seek and turn to the internet and online facilities and programs to complete their anatomy syllabus, of course together with their anatomy books.

- Videos of comparative anatomy were already prepared by the Anatomy and Embryology department and launched on the internet was a good alternative to study the anatomy in dissected rooms. (fig 4)

- Videos of comparative veterinary anatomy produced by College of Vet. Med., University of Minnesota were also available to the students.

- some sites caring with animals and present applied anatomy were also usable by the students. (Figs 18, 19)

- Applied anatomy and diagnostic imaging facilities found on the internet were available to be used by the students (fig 12-14)
- Videos of 3D anatomy on the Utube were another alternative to the students. (fig 11)

i.e. all the online and recorded sources and models of learning anatomy, embryology and histology were available and could be easily used.

The students contacted the staff members via WhatsApp, emails or cell phones to enquire and comment on the lectures (positive point of e-learning is the direct contact with the students).

The semester ended by the end of May.

Ministry of Higher Education in Egypt suggested essays or small research articles on the topics given to the students in not less than 10 pages (Includes abstract, introduction, keywords, topic, discussion and references, not less than five references).

Each student was given one of the topics in anatomy/histology which he/she has studied to write an essay on it. The students had given 1.5 month as a dead line to write and send their works.

Each University gave its instructions: for the students; how to write a research paper and to staff members: how to evaluate this paper.

The evaluation is either pass or failed. 
The practical exam in dissecting rooms, due to the large number of the students, is replaced by MCQ sheet in August (the evaluation is also either pass or failed). (Fig 20)

To face the problem of fair examination of the students, our University established a unite for E-Learning and Questions Bank.

- A studio was prepared and well equipped to register the lectures and helps to upload the power point programs with audio to every staff member need this serves.

- Each department (discipline) has to supply the Questions bank with 800-1000 question in each field.

- In Anatomy\& Embryology department the body systems and topics were divided among the staff members to design the questions in the form of: MCQ, True \& False, Diagrams, Short answers.

- An excel sheet was designed to fill in with every type of questions alone, considering the following points:

- Bloom's taxonomy denoting the questions level. (fig 21)

- The ILO's (Intended Learning Outcomes) of each question to measure skills (from the course specification and description).

- The time of the question (10/15/30/ 60 seconds).

- The Unite of the question (points of this question).

- Hardness of the question (25/50/ 75/ 100).
- Language of the question (English/ Arabic).

- The answers (Max. 4 for the MCQ forms).

- In four columns and the right answer should be marked.

- Two right answers could be present.

Money prizes were decided by the University to the departments on delivering their questions to the Questions Bank Unite for enhancing and encouraging this process.

This un-expected pandemic of Covid 19 forced us to face the term of "blended learning". There is little consensus on the definition of blended learning. Some academic studies have suggested it as a redundant term. However, there are distinct blended learning models suggested by some researchers and educational think-tanks. A well-cited 2013 study broadly defined blended learning as a mixture of online and in-person delivery where the online portion effectively replaces some of the face-to-face contact time rather than supplementing it. "Blended learning" is sometimes used in the same breath as "personalized learn

ing" and differentiated instruction.

There are many components that can comprise a blended learning model, including "instructor-delivered content, e-learning, webinars, conference calls, 
live or online sessions with instructors, and other media and events, for example, Facebook, e-mail, chat rooms, blogs, podcasting, Twitter, YouTube, Skype and web boards"

Wikipedia mentioned 6 models of blended learning which include:

- Face-to-face driver - where the teacher drives the instruction and augments with digital tools.

- Rotation - students cycle through a schedule of independent online study and face-to-face classroom time.

- Flex Blended Learning-Most of the curriculum is delivered via a digital platform and teachers are available for face-to-face consultation and support.

- Labs - All of the curriculum is delivered via a digital platform but in a consistent physical location. Students usually take traditional classes in this model as well.

- Self-blend - Students choose to augment their traditional lear-ning with online course work.

- Online driver - Students complete an entire course through an online platform with possible teacher check-ins. All curriculum and teaching are delivered via a digital platform and face-to-face meetings are scheduled or made available if necessary.

Horn and Staker (2014) mentioned that the majority of blended-learning programs resemble one of four models: Rotation, Flex, A La Carte, and Enriched Virtual. The Rotation model includes four sub-models: Station Rotation, Lab Rotation, Flipped Classroom, and Individual Rotation.

It is important to note that even blended learning models can be blended together and many implementations use some, many, or even all of these as dimensions of larger blended learning strategy. These models, for the most part, are not mutually exclusive.

Blended instruction is reportedly more effective than purely face-to-face or purely online classes. Blended learning methods can also result in high levels of student achievement more effective than face-to-face learning.

Teach Thought Staff (2021) said that obviously, there aren't just 12 types of blended learning. It could be argued that there are thousands of types of blended learning varying by content, scale, technology, learning spaces, etc. They mentioned these 12 types as follows:

\section{Station Rotation Blended Learn-} ing Primarily characterized by: the fixed schedule that guides the 'blending'.

\section{Lab Rotation Blended Learning} Primarily characterized by: the use school computer labs in new ways

3. Remote Blended Learning (also referred to as Enriched Virtual).

Primarily characterized by: students completely coursework remotely and independently. 


\section{Flex Blended Learning}

Primarily characterized by: its versatility to meet the needs of a variety of formal and informal learning processes (schools, organizations, homeschooling, etc.)

\section{The 'Flipped Classroom' Blended Learning}

Primarily characterized by: the retention of traditional learning forms in new contexts (i.e., studying at school and learning at home).

\section{Individual Rotation Blended Learning}

Primarily characterized by: the personalization of student learning as determined by individual schedules that have the chance to better meet the needs of each student

\section{Project-Based Blended Learning}

Primarily characterized by: the use of online resources to support projectbased learning.

\section{Self-Directed Blended Learning \\ Primarily characterized by: the ex- change of traditional academic work for student-centered inquiry.}

\section{Inside-Out Blended Learning}

Primarily characterized by: student movement between digital and physical spaces.

\section{Outside-In Blended Learning}

Primarily characterized by: student movement between digital and physical spaces; the potential authenticity of student work.

\section{Supplemental Blended Learn- ing}

In this model, students complete either entirely online work to supplement their day-to-day face-to-face learning, or entirely face-to-face lear-ning experiences to supplement the learning gained in online courses and activities.
The big idea here is supplementingcritical learning objectives are met entirely in one space while the 'opposite' space provides the student with specific supplementing experiences that the other did not or could not provide.

12. Mastery-Based Blended Learning

Students rotate between online and face-to-face learning (activities, assessments, projects, etc.) based on the completion of mastery-based learning objectives.

Gitonga (2020) mentioned top 6 benefits of blended learning as:

1. Individualized Learning

2. Immediate Feedback

3. Varied Modes of Learning

4. Collaboration

5. Parental Involvement

6. Attainment of Future Work Skills

She added that online learning requires one to inculcate certain life skills for it to be successful. Students are required to practice self-discipline, time management, and online etiquette. They should also be digitally savvy to operate in the online environment. Sending emails and presentation skills are nurtured through exposure to technology use. All these skills are essential in the $21^{\text {st }}$ century and will prepare the students for future work in whichever career they choose to pursue.

In the last winter semester as well as the $1^{\text {st }} \& 2^{\text {nd }}$ semesters $(2020 / 2021)$ the same procedures were also adopted: 
- Blended learning, any preferred type, (50\% online and $50 \%$ face to face lectures).

- Physical distancing, minimizing the student's number in dissecting rooms. (Fig 22)

- Using the pro-dissected cadavers for the practical lessons.

- Replacing the practical exams with sheets with photos. (fig 23)

- Oral examinations were held in some universities in the openair areas, gardens and playgrounds of the faculties.

- The contact of the students and staff members still via WhatsApp groups and the universities platforms.

A very good positive result of this pandemic which I noticed, is the cooperation between staff members in different universities in the world sharing their experiences, ideas, power points and programs and made it available to every staff member in other faculties. (May I mention in special within the USA and the Amer. Ass. Vet. Anat.)

To be fair, we noticed some negative points that marred the educational process in general, as follows:

1)Some students do not own computers.

2)The inefficiency of the Internet in most of times.

3)The lack of experience of some faculty members to some modern technologies from using virtual classrooms or recording lectures with audio or uploading them to the university platforms.

4) A very important point in this regard is the student's lack of using the microscope and the act of dissection by himself, which is a very important skill that cannot be dispensed with to gain the necessary sensitivity needed in surgery and obstetrics later.

\section{Conclusion}

The future (after Corona era) will be a mixture of face-to-face and online or distance learning i.e. blended learning.

\section{References}

Michael B. Horn and Heather Staker (2014): Blended: Using Disruptive Innovation to Improve Schools, San Francisco: Jossey-Bass.

Pollyanne Gitonga (2020): Top 6 Benefits of Blended Learning

https://elearningindustry.com/6benefits-blended-learning-looking-beyond-covid. (Retrieved on $1 / 4 / 2021)$
A.S.Saber; K.M.Shoghy and
S.A.Mohammed (2016): Plasticine Modeling as Alternative in Teaching Veterinary Anatomy. J. Vet. Anat., Vol. 9, No. 1:47 - 61

Samy A. Azer and Sarah Azer (2016): 3D Anatomy Models and Impact on Learning: A Review of the Quality of the Literature. 
Teaching anatomy and Covid-19.

A. S. Saber

Health Professions Education 2, :80-

98

Christensen Institute and blended-

learning.org (retrieved on 3.4.2021)

https://www.teachthought.com/learning/12-

types-of-blended-learning/

(retrieved on 4.4.2021)

Wikipedia: the free encyclopedia (retrieved on 16.3.2021)

Author address

Prof. Dr. Ashraf Sobhy Saber

saberashraf 2@yahoo.com
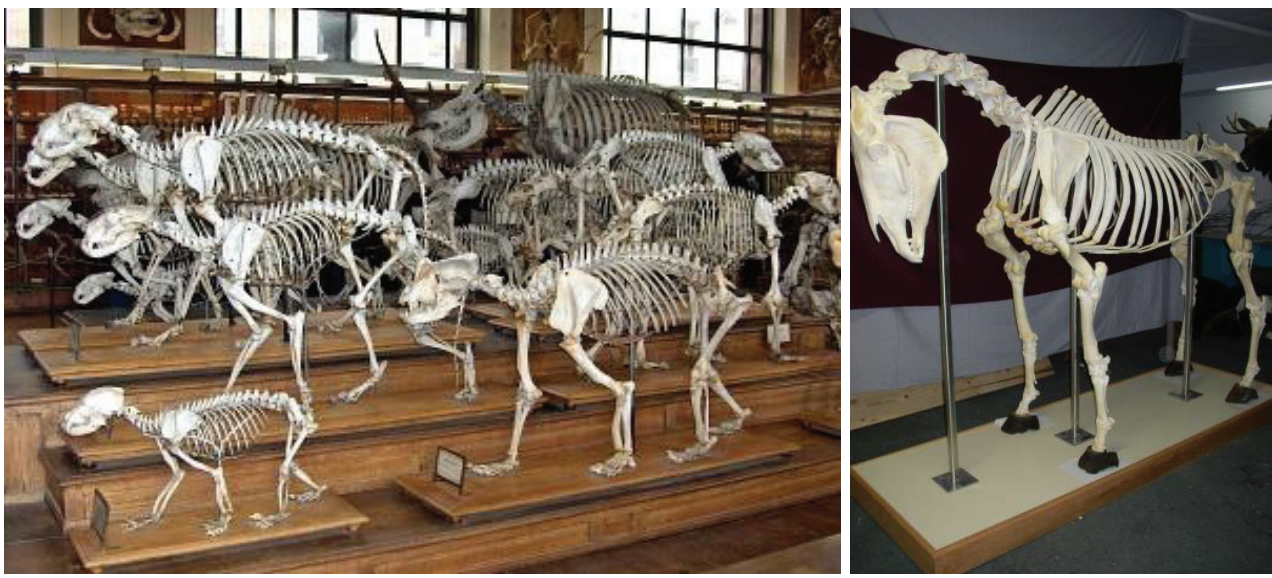

Fig (1): animal skeletons and bones in the museums (Source: Wikipedia) 

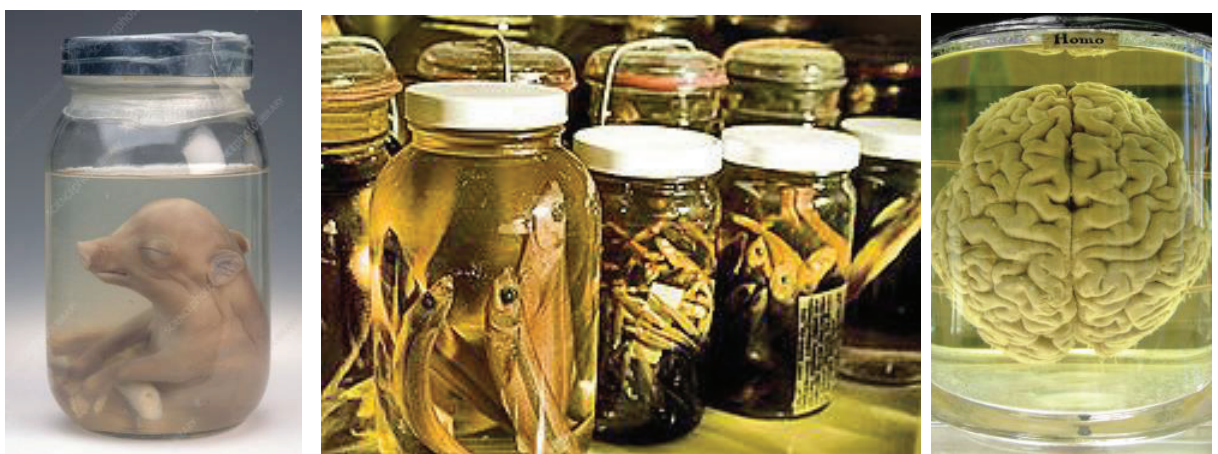

Fig (2): formalin preserved specimens (piglet, fishes and human brain) (Source: Wikipedia)
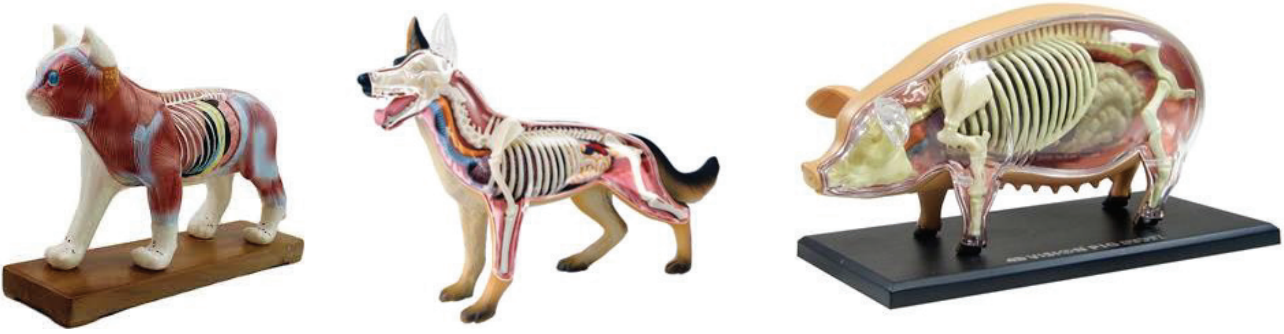

Fig (3): Anatomical models (cat, dog, and pig) (Source: Wikipedia)

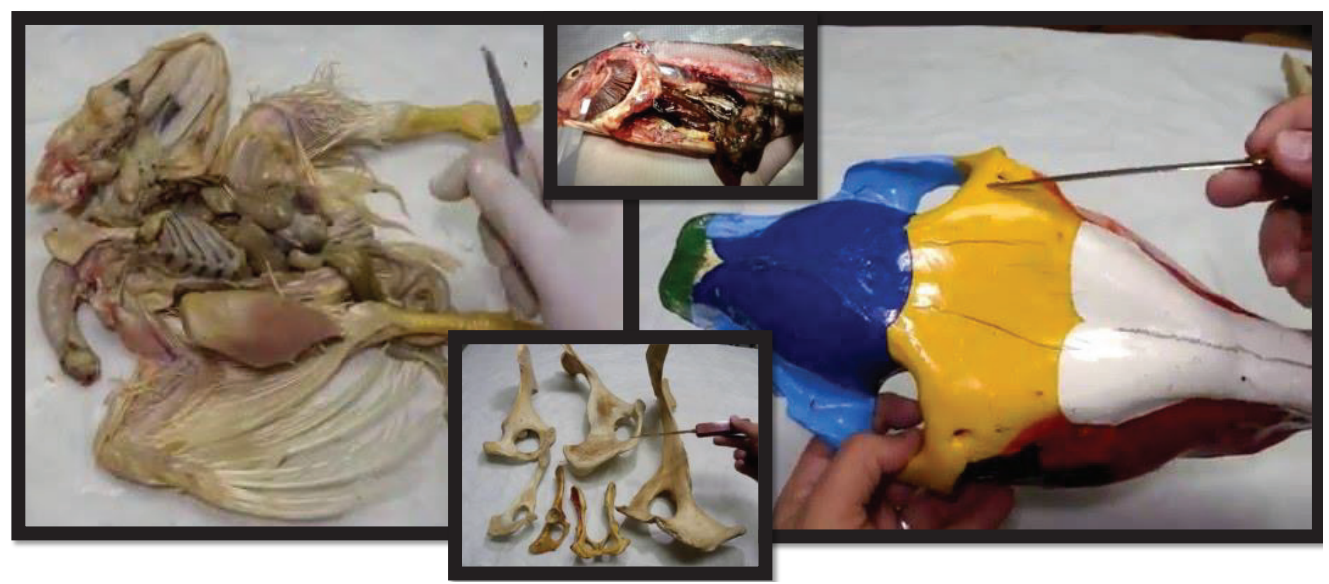

Fig (4): Videos of comparative prepared by staff members and are available on the internet freely 

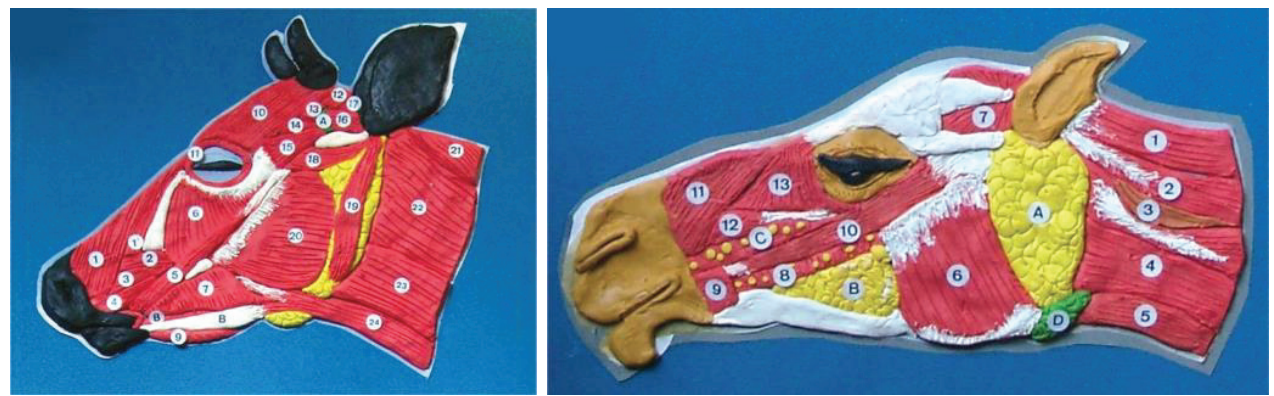

Fig (5): Plasticine plate of superficial muscles of the face of the cow and camel (Saber et al, 2016)
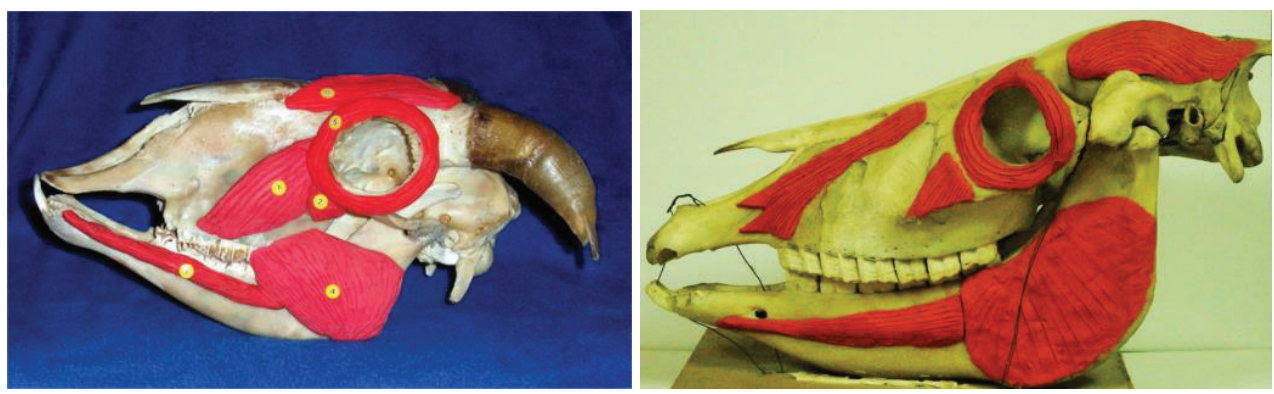

Fig (6): Plasticine shaping of some muscles of the face on the skull of the sheep and horse (Saber et al, 2016)
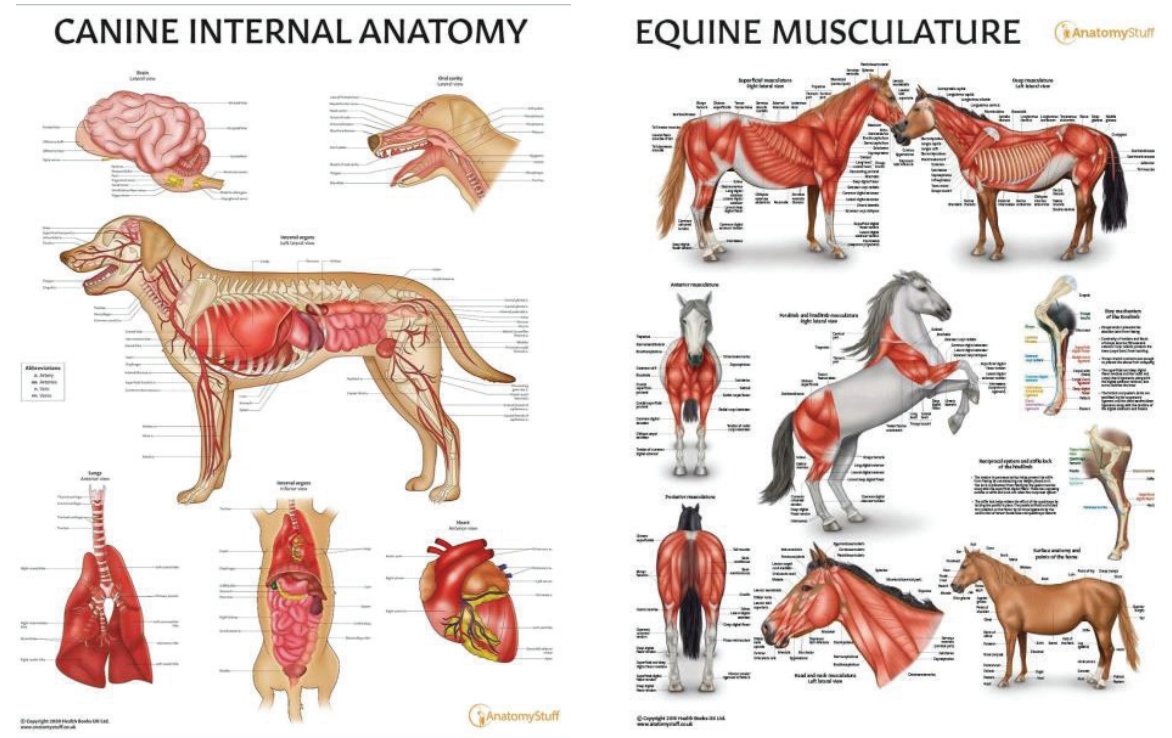

Fig (7): Anatomical charts (Source: Wikipedia) 
Teaching anatomy and Covid-19.
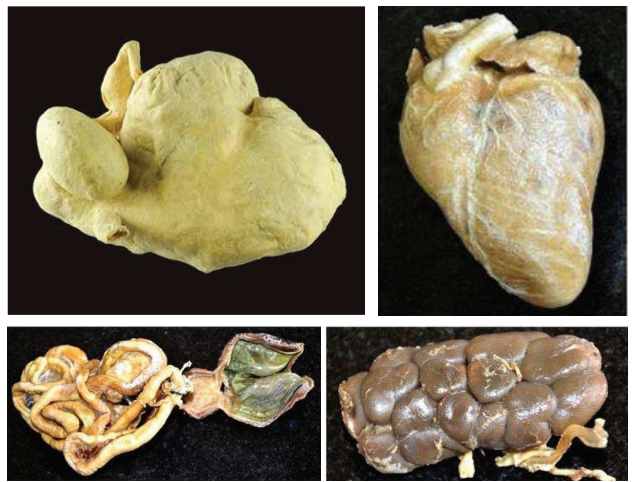

A. S. Saber
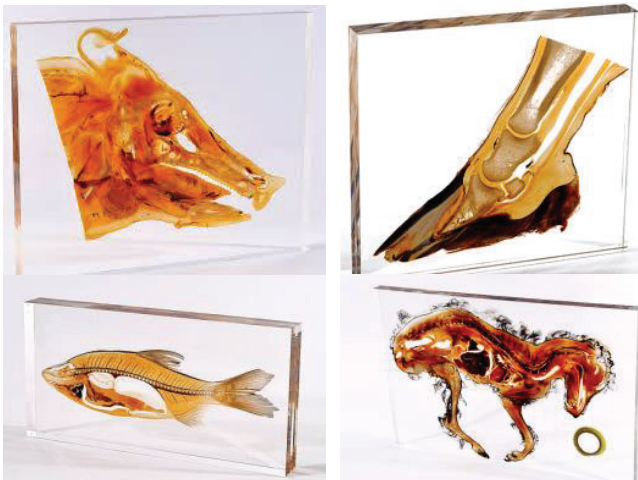

Fig (8): Plastinated organs and sheets (Source: Wikipedia)
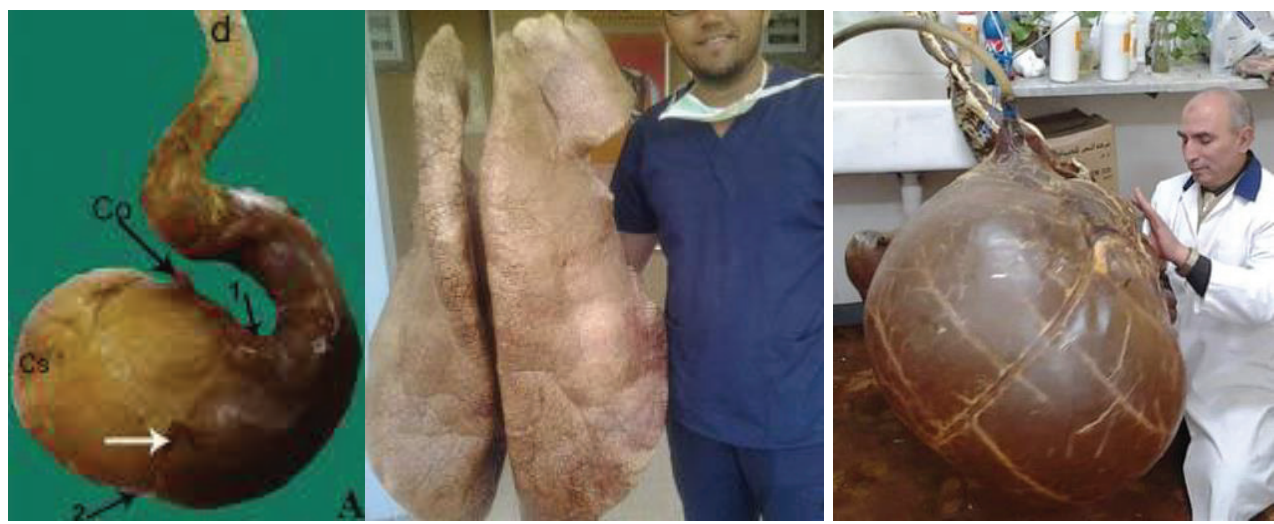

Fig (9): Air-dried hollow organs
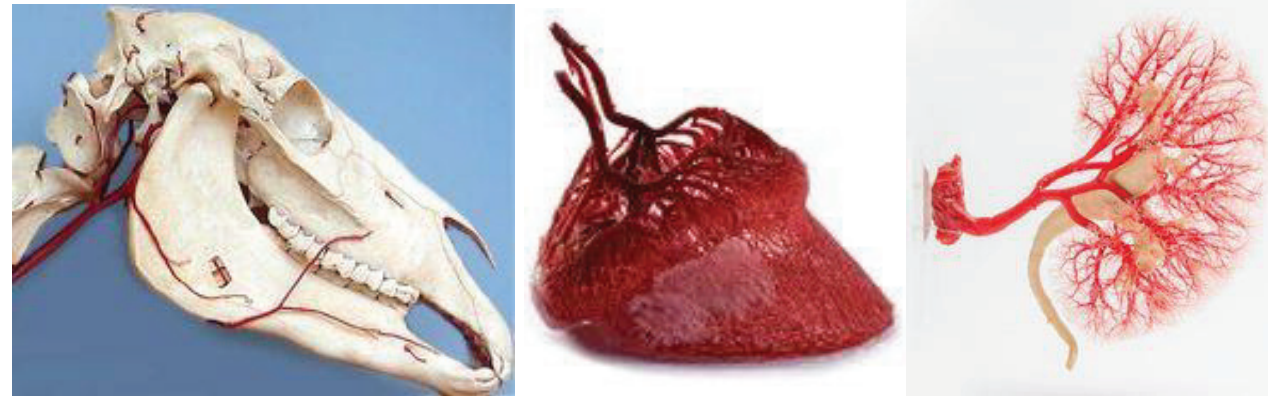

Fig (10): Corrosion casts of a horse's skull, hoof and kidney (Source: Wikipedia) 

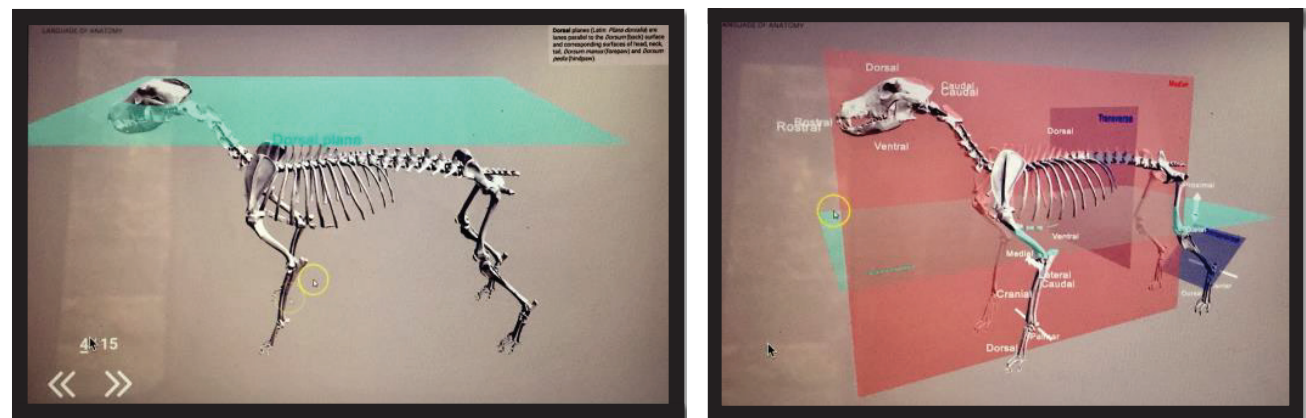

Fig (11): 3-D diagrams
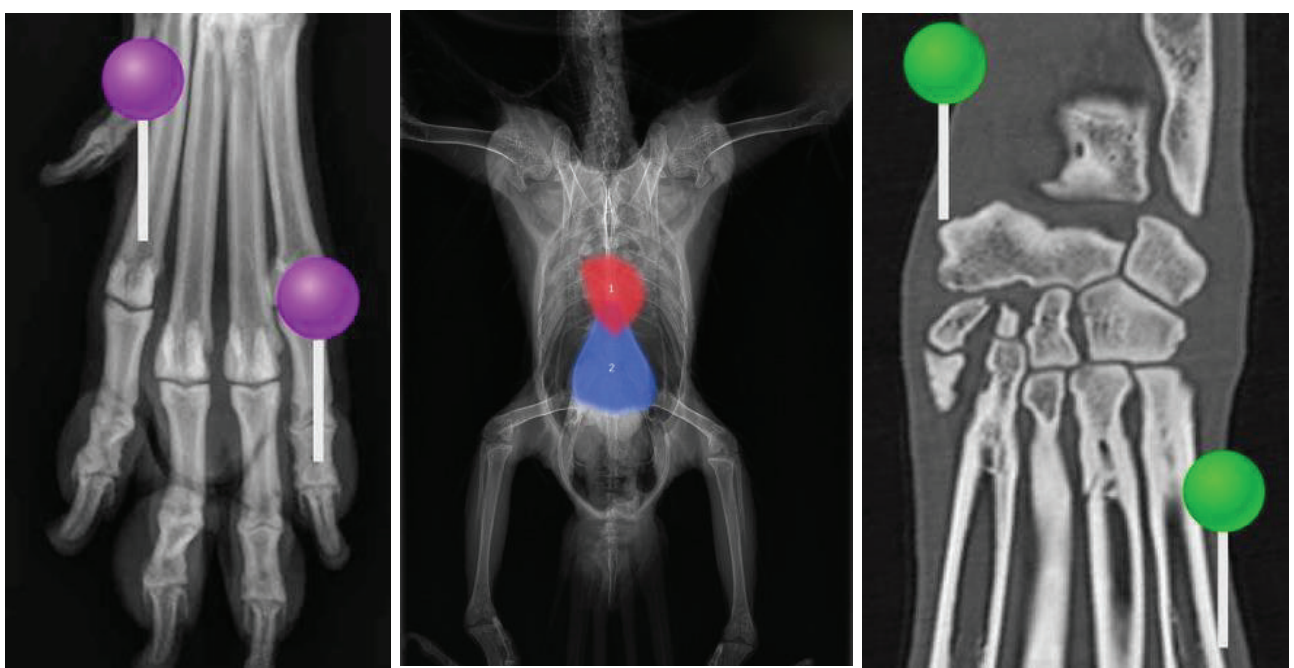

Fig (12): Plane X-ray images are tool for studying and examining applied and imaging anatomy. (Source: Wikipedia)
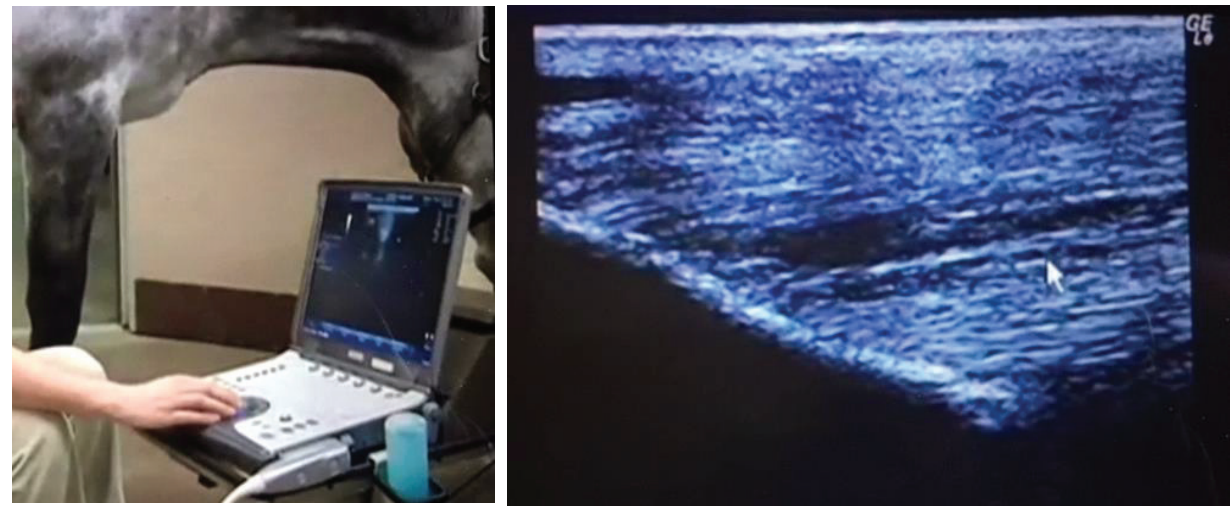

Fig (13): MRI image of a horse's tendon (Source: Wikipedia) 

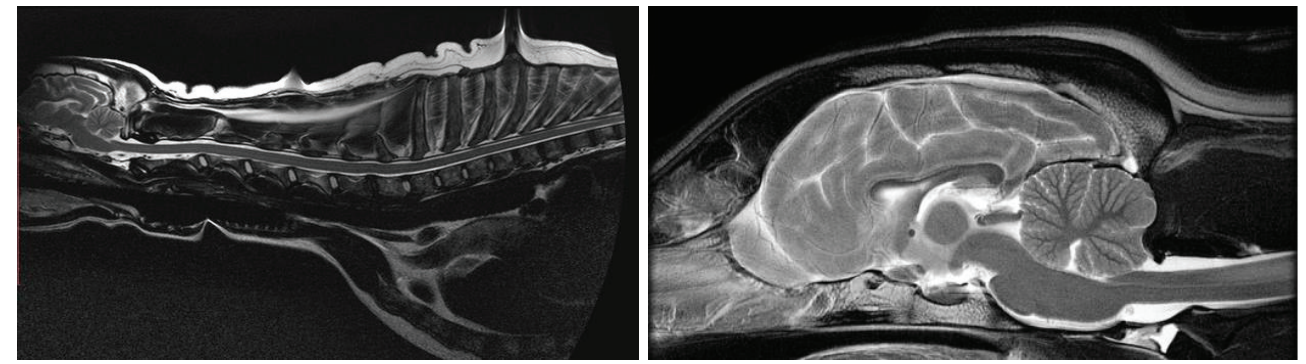

Fig (14): CT image of dog neck and thorax \& brain (Source: Wikipedia)
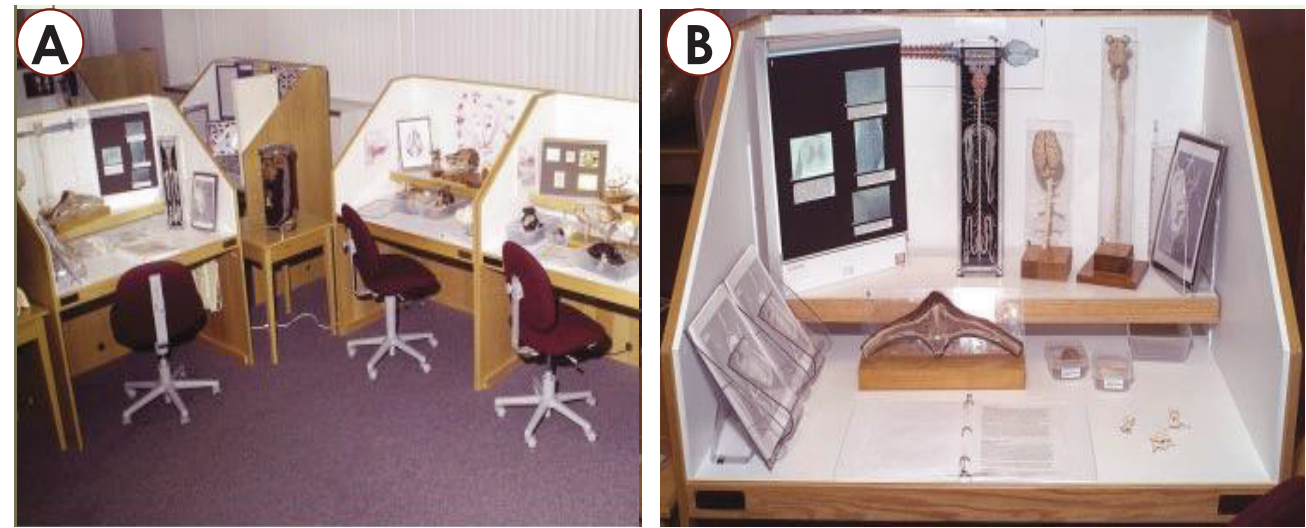

Fig $(15, \mathrm{~A}, \mathrm{~B})$ : Anatomy modules
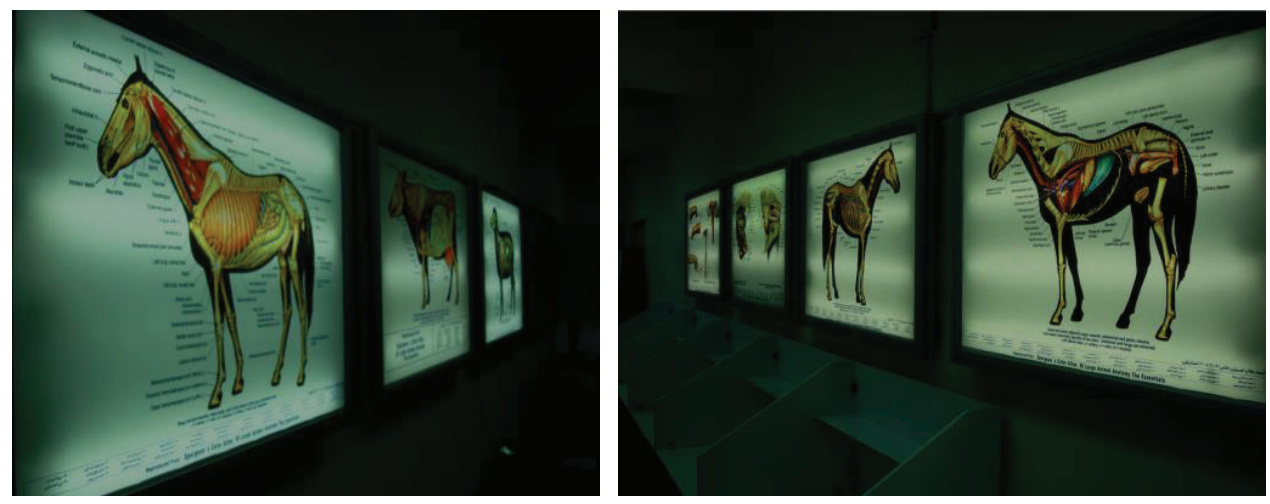

Fig (16): Lighted coloured comparative anatomy charts hanged in the corridors (Fac. Vet. Med., Cairo University). 


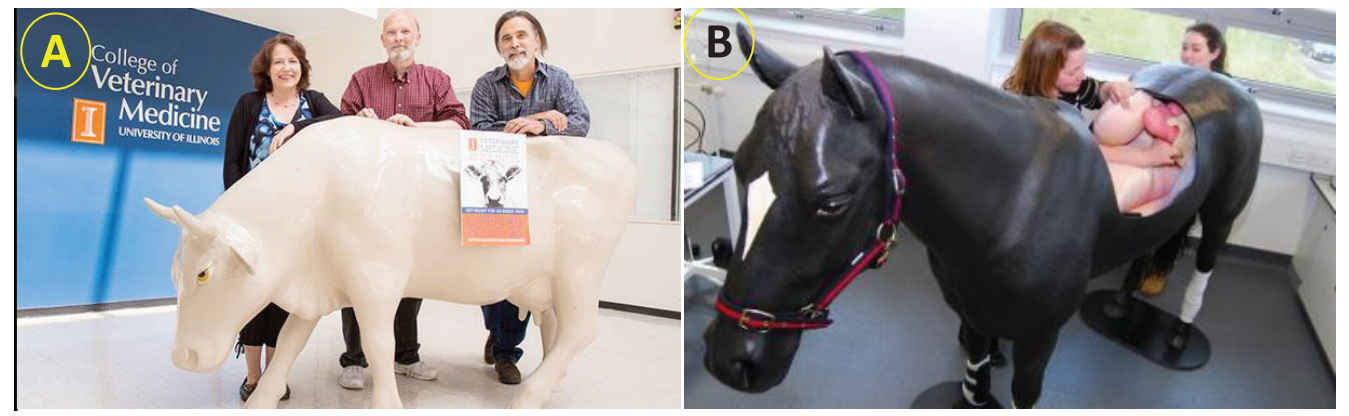

Fig (17 A, B): Virtual 3-D model to teach cow anatomy. The 3-D model shows the skeleton, heart, lungs, four-chamber stomach, spiral colon, liver, gall bladder, kidneys, uterus and ovaries, as well as the major blood vessels. University of Illinois, USA. \& The equine simulator at the Royal (Dick) School of Veterinary Studies contains large intestines and other organs made of latex. These can be inflated to different degrees to help familiarize students with the condition. (Source: Wikipedia)
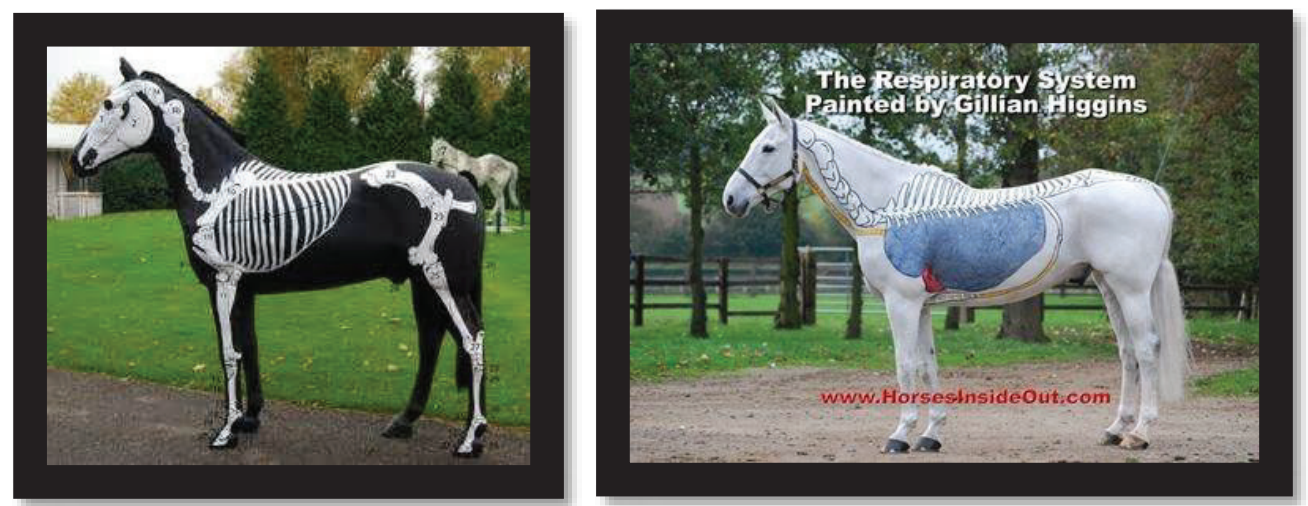

Fig (18): Using live animals for teaching applied anatomy (Source: Wikipedia)
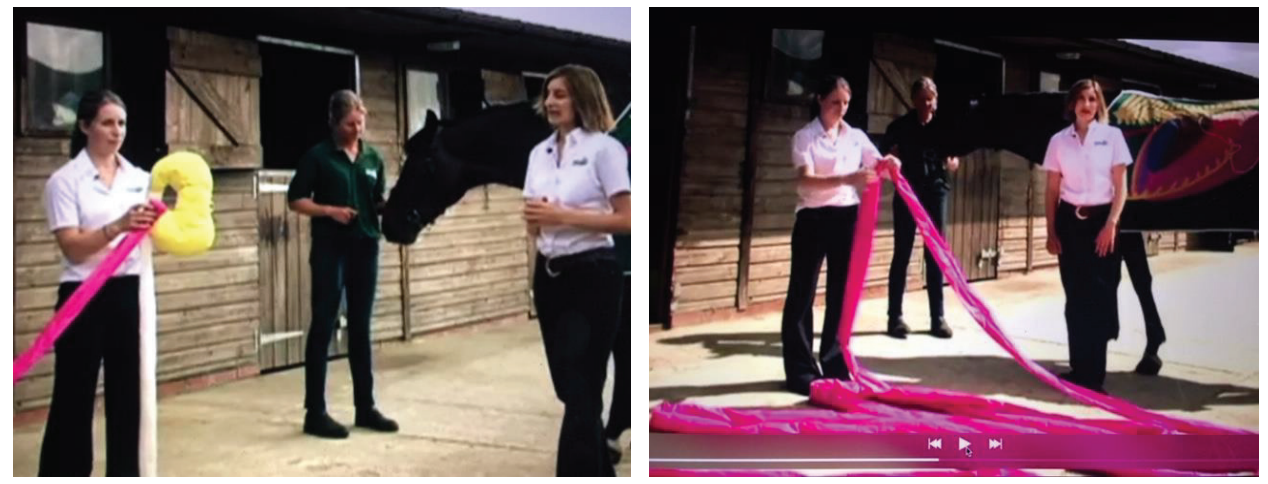

Fig (19): Equine and intestine simulator for the riders in some horse studs. (Source: Wikipedia) 


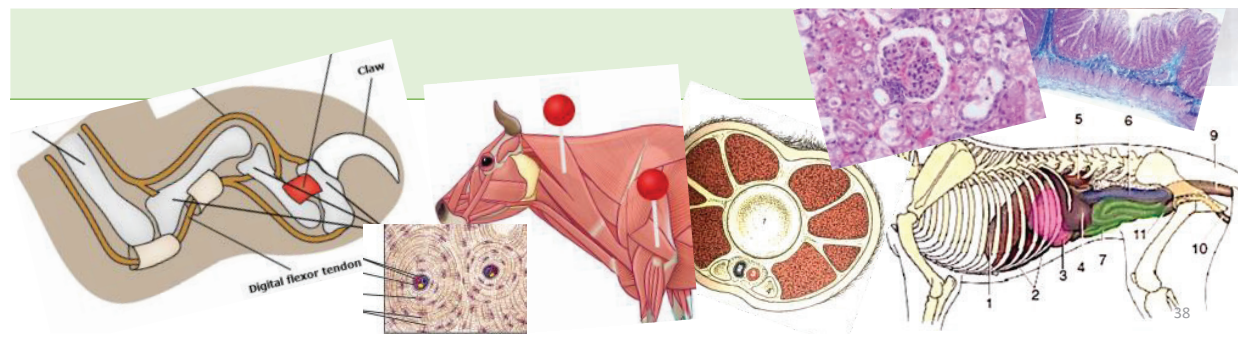

Fig (20): Some diagrams used in examination sheets.

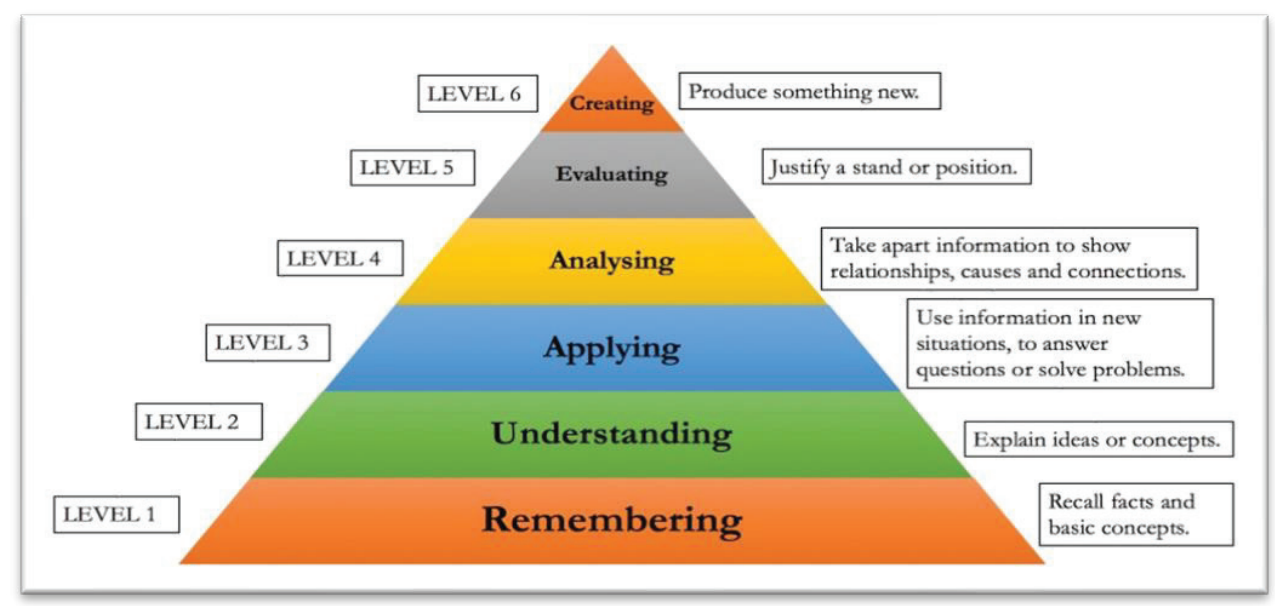

Fig (21): Bloom's taxonomy pyramid for measuring questions level

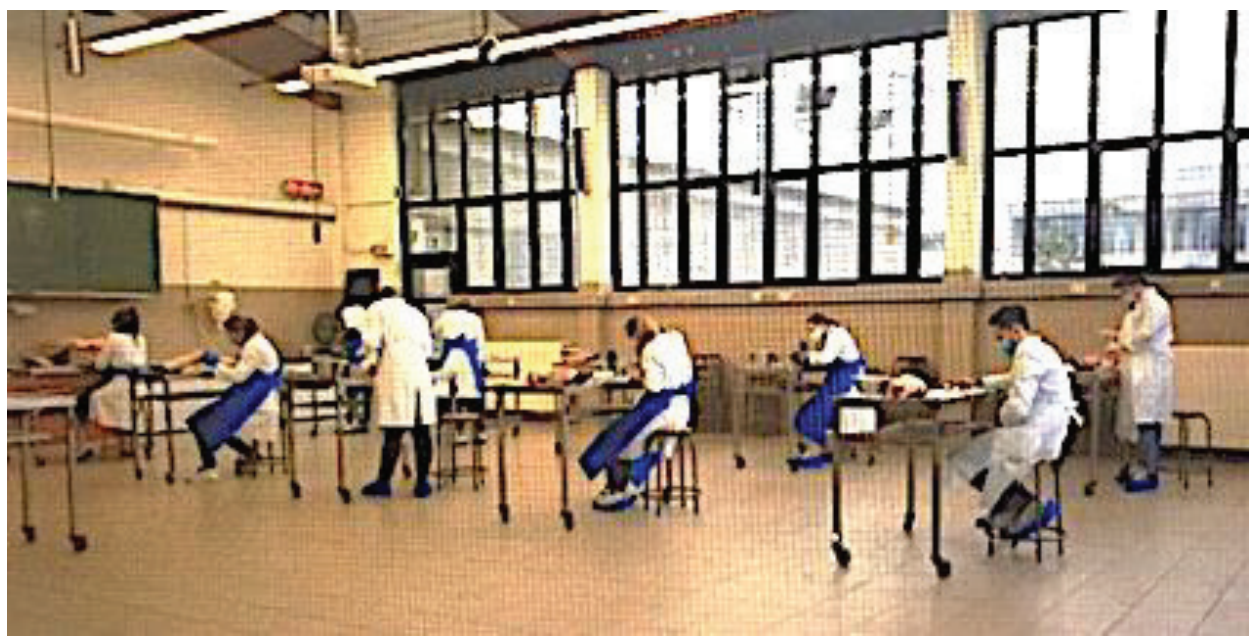

Fig (22): Physical space in the practical examination (held in dissection hall) 


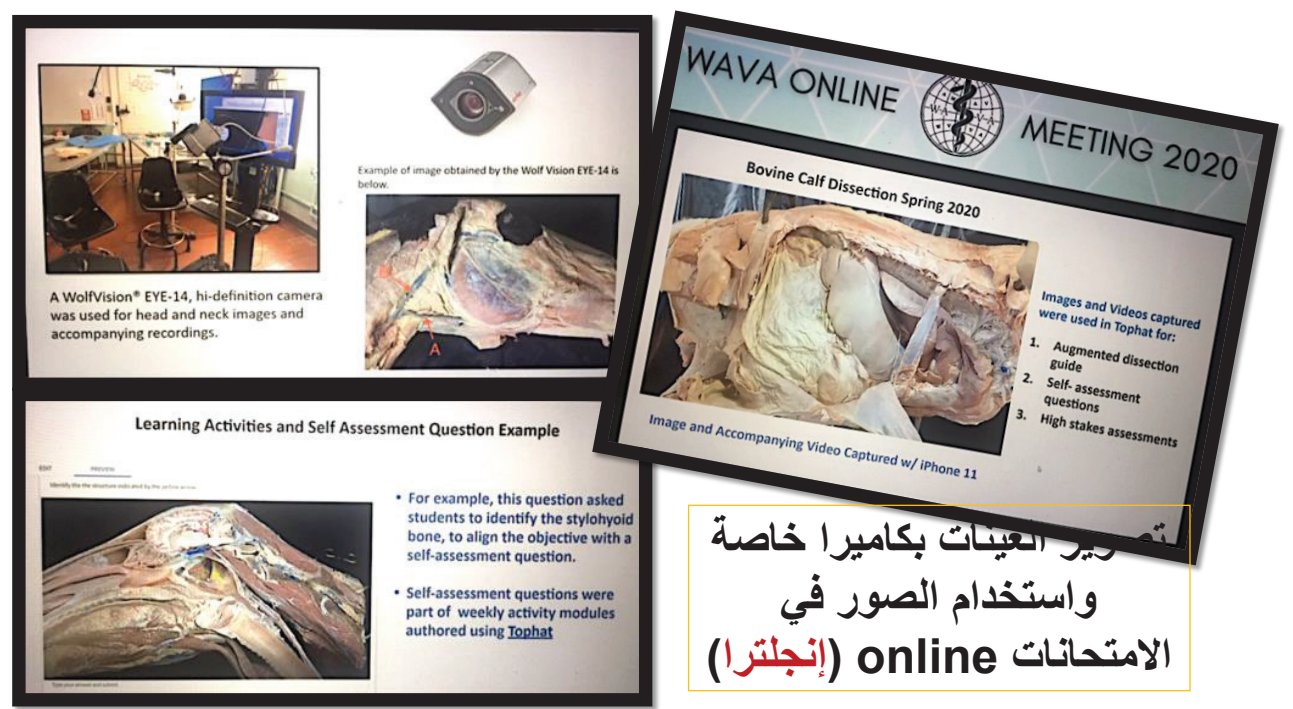

Fig (23): An additional tool for capturing photos for teaching and online examining anatomy, 